\title{
Don Lindberg: Best Friend and Colleague
}

\author{
Charles KALINA M.S., M.B.A. ${ }^{1}$ \\ U.S. National Library of Medicine (retired) \\ Silver Spring, MD. U.S.A.
}

Keywords: Donald A.B. Lindberg M.D., U.S. National Library of Medicine

Classically and appropriately, festschrifts tend to remember an individual's professional achievements. Those were Don's many. But my memories include Don as a person and as my best friend since high school days, a sentiment I trust was mutually returned.

The high point of our high school experience was a 1949-50 senior year, joint ownership of 1929 Chandler sedan - purchased for $\$ 60$. Don was the designated driver, with his driver's license mailed for $\$ 1$, not from a Cracker Jack box, but the State of Missouri. Those were calmer Truman days, with a better feeling of trust in society. In retrospect, it must have been those of our permissive parents, reflecting their faith in our budding teen competence,

In addition to providing mobility around hometown Brooklyn, the Chandler survived a round trip to northern Virginia (to visit a school friend who transferred to a local boarding school in his senior year) - with only a detached muffler in front of Washington National Airport. We walked across the tarmac to a hanger where we borrowed some tools to repair it - another memory of action of faith that could scarcely be repeated some seventy years later.

Then, we grew up.

We resold the Chandler for what we paid and, well-prepared at Poly Prep Country Day School, dispersed to college, medical school, and graduate science training - with a break in the Army for me. I made a quick trip from my then-rocket scientist duties to attend Don's marriage in Washington to his darling Mary in 1957. Later, we enjoyed a vacation as joint crew on a rented motorboat, anchoring on the Hudson River in the shadow of West Point and pumping out a rudder mounting leak on Long Island's Great South Bay.

Don joined me as my best man at my wedding in Chicago in 1962. I was cheered on that occasion by Mary accompanied by their first newborn, Don Jr.

By that time, my interests as a consultant broadened, and I became a community agency, state health systems planner for Rhode Island, residing in Boston. Don was increasingly recognized as an authority in medical informatics and was on the University of Missouri's medical faculty.

A commonality of health expertise made it possible for us to keep in touch, notwithstanding the distance involved. I visited Don's department in Missouri and shared developments in the art of health planning - and enjoyed diving into Columbia's swimming quarry. Boston's popularity as a scientific conference site provided periodic opportunities for Don to visit Boston. We enjoyed dining at Pier Four in Boston Harbor.

1 Corresponding author: kalinac@verizon.net 
As an inveterate photographer, Don would document the visits, a record I continue to cherish.

After federal funding revisions in the $1980 \mathrm{~s}$, health planning became the responsibility of state health departments. I no longer perceived the state of Rhode Island took advantage of my capabilities and interests. So, in 1986, I joined (hopefully to its reward) the National Library of Medicine (NLM) for the rest of my professional career.

At the time, Don was concerned about preserving the original scientific research that was available on NLM's multi-media platforms. Don knew that as electronic and other access to selected information improved, preserving the growing corpus of biomedical research (stored electronically and on NLM's shelves) became increasingly problematic. Although media preservation concerns were widespread, the topic received limited and isolated attention with little remedial collaboration.

More specifically, electronic media faced the prospects of obsolescence and the possible deterioration of materials, such as optical discs. Paper (science's original mass medium) simultaneously needed preservation from increased decline caused by age (in some cases) and a $20^{\text {th }}$-century abandonment (by publishers of biomedical books and journals and many others) of more expensive permanent, acid-free paper. Overall, NLM's information storage expertise and mission as the nation's medical library provided a significant venue to initiate an innovative preservation program.

With Don's continued interest and encouragement, NLM vigorously pursued preservation activities for several years. NLM formed an active permanent paper task force of paper manufacturers, publishers, and information users, and pursued other, specific preservation interests with Abbey publications, a leading journal for preservation interests.

NLM additionally testified at pertinent Congressional committees. NLM supported the U.S. Senate and House of Representatives passage of PL 101-423 in September 1990, signed by President George Bush into law in October 1990, which required the use of permanent, acid-free paper in federal publications. With live voice and guitar renditions of 'Songs of Paper' that was part of a hearing, a national task force of eight publishers, three major paper manufacturers, and 22 concerned institutional representatives led broad paper and other media preservation reforms in October 1991.

In 1993 Don's seconding appointment as director of the High-Performance Committee on Communications and Information Technology (HPCCIT) in the President's Office of Science Technology Policy attested his national reputation. I accompanied him as Executive Secretary. Developing policy direction was not the only task of the office, which also served as an incubator for entrepreneurial talent within the then-nascent U.S. digital revolution. After two formative years, Don returned to the fulltime helm of NLM. I soon resumed my NLM tasks, and the Library remained a source of personnel talent for the HPCCIT in subsequent assignments.

Don continued his NLM directorship for another two decades. I retired in 1997 to devote more time to developing some family real estate property in Boston; but I continued to reside in Maryland. This made it possible to enjoy Don's company and pool and continue, with Mary, to crew on the "L' bon Femme" on the Potomac and the Chesapeake, all 32 feet and 220 horsepower of it.

Today I enjoy a quiet, well-earned retirement, which is more the reason to treasure one's twilight years. Yet, it is tragic many retirement years were taken from Don due to his accidental passing. My life was richer by knowing him and following his inspiring example as a leader, mentor, and friend. While Don may be gone, his memory continues to thrive deep within me. 